\title{
Guillain-Barré syndrome as a cause of acute flaccid paralysis in Iraqi children: a result of 15 years of nation-wide study
}

Jagar Jasem ${ }^{1,2^{*}}$, Kawa Marof ${ }^{3}$, Adnan Nawar $^{4}$, Yosra Khalaf $f^{5}$, Sirwan Aswad ${ }^{3}$, Faisal Hamdani ${ }^{5}$, Monirul Islam $^{6}$ and Andre Kali ${ }^{7}$

\begin{abstract}
Background: Guillain-Barré syndrome (GBS) is the most common cause of acute flaccid paralysis (AFP) in the post-poliomyelitis eradication era. This is the first study done to identify the epidemiology, clinical features, and outcome of GBS in Iraqi children over 15 years.

Methods: The surveillance database about AFP cases < 15 years reported during January 1997-December 2011 was used.

Results: GBS represented $52.5 \%$ of AFP cases, with an incidence of 1.33 case/100,000 population < 15 years/year. There was a higher incidence in the Southern provinces, age group 1-4 years, males, and outside the capital city of province, with no significant seasonal variations $(p=.22)$. Survival probability after the 1 year of onset for those with respiratory muscle involvement was .76 (95\% Cl: .60-.86), versus .97 (95\% Cl: .96-.98) for those who did not develop it $(p<.001)$; and .97 (95\% Cl: .96-.98) for those living inside the capital city, versus .94 (.93-.95) for those living outside $(p=.001)$. Cumulative incidence of residual paralysis for patients living inside the capital city was .21 (95\% Cl: .18-.24), versus .27 (95\% Cl: .25-.29) for those living outside $(p<.001)$.

Conclusions: The incidence, age and gender distribution, and seasonality of GBS among Iraqi children is similar to those reported from other previous studies. It is the most important cause of AFP, especially in those between the age of 1 to 4 years living in rural areas.
\end{abstract}

\section{Background}

Guillain-Barré syndrome (GBS) is mostly an acute inflammatory demyelinating ascending polyradiculoneuropathy [1-3]. Flu-like illness or gastroenteritis precedes the onset of paralysis by 6 weeks in about two-thirds of patients [3]. The culprit infectious agent often remains unrecognized, but Compylobacter jejuni Mycoplasma pneumonia, and cytomegalovirus are commonly reported triggering pathogens. Molecular mimicry between structural components of both pathogens and myelin sheath of peripheral nerves, with subsequent cross-reaction of antibodies with the latter, is a commonly proposed hypothesis for the pathogenesis of disease [3-6].

\footnotetext{
* Correspondence: jagar.jasem@osumc.edu

'School of Medicine/ Faculty of Medical Sciences/ University of Duhok, Nakhoshkhana Street, Duhok, Kurdistan Region, Iraq

${ }^{2}$ Internal Medicine, Ohio State University, Columbus, Ohio, USA

Full list of author information is available at the end of the article
}

Worldwide, GBS is considered the most common cause of acute flaccid paralysis in the post-poliomyelitis eradication era [5-14]. It affects people in various geographical locations and virtually all age groups [15]. Similar studies about the epidemiology and clinical features of GBS yield a wide range of minor to major differences [4,10,15-18]. Information about the epidemiology of the disease can give insights into the changing patterns of the disease incidence following exposure to new potential provoking factors [16]. Measuring the outcome of the disease in terms of mortality and morbidity can help direct attention towards modifying the risk factors of adverse disease outcomes. This is the first study done to identify the epidemiology, clinical features, and outcome of GBS in Iraqi children over 15 years of study.

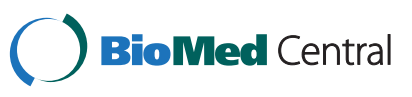

(c) 2013 Jasem et al.; licensee BioMed Central Ltd. This is an open access article distributed under the terms of the Creative Commons Attribution License (http://creativecommons.org/licenses/by/2.0), which permits unrestricted use, distribution, and reproduction in any medium, provided the original work is properly cited. 


\section{Methods}

The surveillance database about acute flaccid paralysis (AFP) cases under the age of 15 reported from Iraq during January 1997 to December 2011 was used in the current study. AFP surveillance is an essential strategy of the Polio Eradication Initiative adopted by the World Health Organization (WHO) in 1988. AFP is defined as "any child under 15 years of age with acute flaccid paralysis (including GBS) or any person of any age with paralytic illness if polio is suspected". AFP information is routinely included in the weekly and monthly reporting system from the Preventive Health Department (PHD) in the Directorate General of Health (DGoH) of every Iraqi province, even if there is no reported case (routine surveillance "zero-reporting"). Notifications are done via mailing the standard communicable notification forms designed by the Iraqi Ministry of Health to the Communicable Disease Control Unit (CDCU) of the regional PHD. Active surveillance for the suspected cases of AFP is ideally done within 48 hours via a designed investigating team from the CDCU visiting the reporting sources (hospitals, rehabilitation centers, or private clinics). Case investigation is done using a WHO-standardized form [19].

Two stool specimens are collected from each suspected case with an interval of 24-48 hours between collections, given that no more than two months have elapsed since the onset of paralysis. Following collection, the specimens are kept in a cold box to be sent for the National Polio Laboratory in Baghdad. At least 60 days after the onset of paralysis, all surviving patients are reexamined by an expert committee for residual paralysis. The diagnosis of GBS was made based on clinical evaluation and cytochemical analysis of the cerebrospinal fluid retrieved via conducting a lumbar puncture test of the suspected cases.

There is no clear classification for "urban" and "rural" areas in Iraq. Hence, the most approximate encounter for that fact is via dividing each Province into areas inside and outside the Capital City of each; referring to more urban and more rural areas, respectively.

The study was approved by the Ethical Committee of the Faculty of Medical Sciences/University of Duhok, Duhok, Iraq and the Institutional Review Board (IRB) of the University of Nebraska Medical Center, Omaha, Nebraska, USA. The statistical analysis was done using SPSS 18 for Windows/MAC, (PASW ${ }^{\circ}$ Statistics GradPack 18). Statistical analyses included: Chi-square test, univariate Kaplan-Meier survival analysis and stratified log-rank tests. All tests were two sided with .05 level of significance.

\section{Results}

A total number of 5027 cases were reported from Iraq between January 1997 and December 2011. Out of these,
53 cases were excluded as they were not AFP (nutritional deficiencies and skeletal diseases). A total of 4974 cases of AFP were used in the final analysis. GBS represented more than half of the reported cases $(\mathrm{N}=2611$, $52.5 \%$ ) (Table 1), corresponding to an annual incidence of 1.33 case/100,000 population under the age of 15 years (95\% CI: .97-1.68). There was a higher incidence in the Southern provinces compared to the Central and Northern ones (Figure 1). The vast majority of cases belonged to the age group 1-4 years old (Figure 2). Male-female ratio was $1.35: 1$. About $65 \%$ of cases occurred outside the capital city of province of more rural social characteristics. Cases were reported throughout the year with the highest number being in January (261) and the lowest in August (173) (Figure 3). This monthly variation was not statistically significant $(p=.22)$.

Fever was observed in 1358 (55.4\%) of cases, and progression of paralysis to the maximum within 4 days of onset occurred in $2450(97.1 \%)$ of cases. At least 60 days from the onset of paralysis, 619 (24.6\%) of cases had residual paralysis and 118 (4.8\%) others died (Table 2).

The probability of survival after the 1 year of onset for those with respiratory muscle involvement was .76 (95\% CI: .60-.86), versus .97 (95\% Cl: .96-.98) for those who did not develop respiratory muscle weakness $(p<.001)$ (Figure 4). Kaplan-Meier analysis of household location, gender, and age showed that only household location was significantly associated with the decreased probability of survival. The cumulative survival for patients living inside the capital city of province was .97 (95\% CI: .96-.98), versus .94 (.93-.95) for those living outside the capital city of province $(p=.001)$ (Figure 5). This effect was eliminated when stratified log-rank test was performed for both respiratory muscle paralysis and household location $(p=.21)$. Likewise, Kaplan-Meier analysis of household location, gender, and age showed that both household location and age were significantly associated with increased cumulative incidence of residual paralysis. The cumulative incidence of residual weakness

\section{Table 1 Causes of acute flaccid paralysis in Iraqi} children, 1997-2011

\begin{tabular}{ll}
\hline Cause & Number (\%) \\
\hline Guillain-Barré syndrome & $2611(52.5)$ \\
Traumatic neuritis & $715(14.4)$ \\
Meningitis/Encephalitis & $292(5.9)$ \\
Poliomyelitis & $166(3.3)$ \\
Myopathy & $89(1.8)$ \\
Hypokalemia & $74(1.5)$ \\
Unknown & $568(11.4)$ \\
Others & $459(9.4)$ \\
Total & $4974(100)$ \\
\hline
\end{tabular}




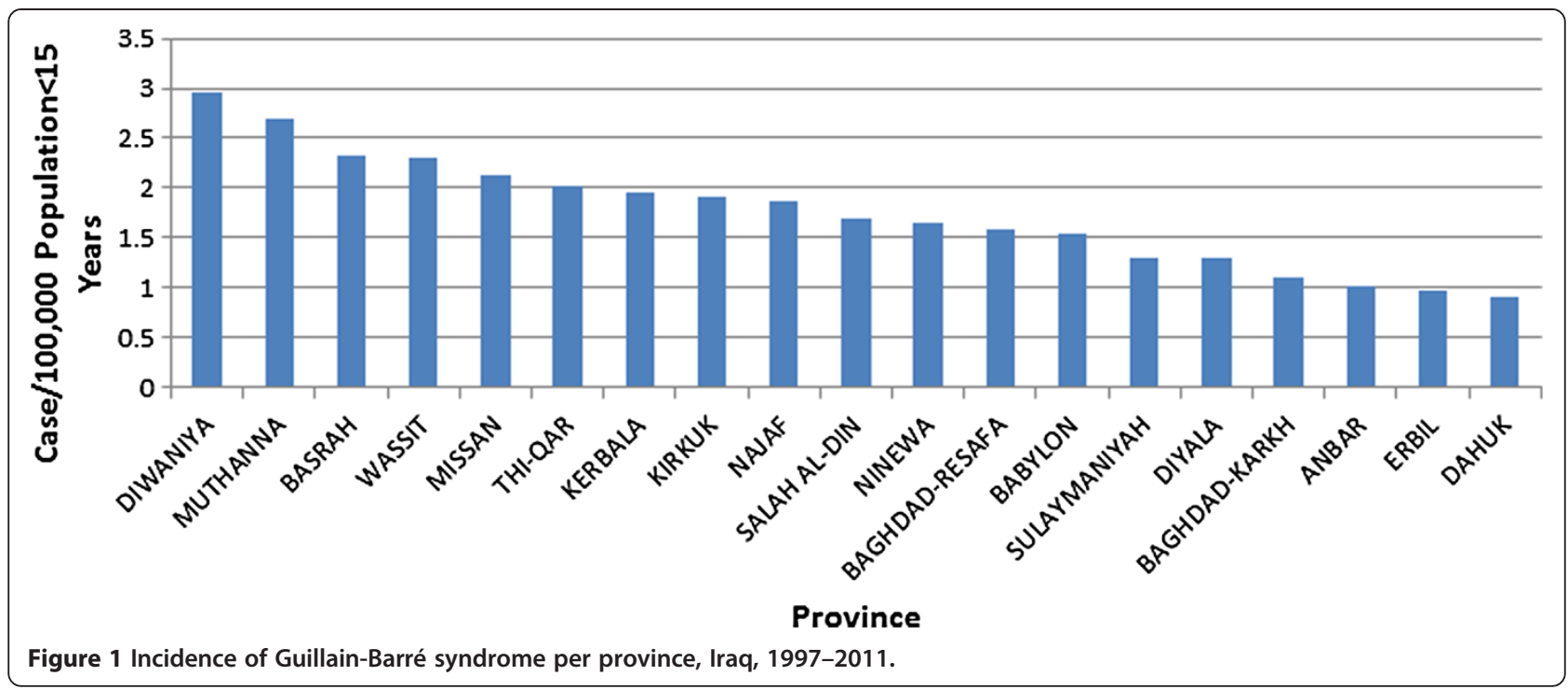

increased with age was: .22 (95\% Cl: -.20-.24) for those below the age of 5 years and .35 (.29-.41) for those above the age of 5 years $(p=.001)$ (Figure 6). The cumulative incidence of residual paralysis for patients living inside the capital city of province was .21 (95\% CI: .18-.24), versus .27 (95\% CI: .25-.29) for those living outside the capital city of province $(p<.001)$ (Figure 7). This effect was maintained when stratified log-rank test was performed for both age and household location $(p=.001)$.

\section{Discussion}

The annual incidence among Iraqi children was 1.33/ 100,000 population under the age of 15 years. This rate is at the upper limit of the reported international range of .34-1.34 cases/100,000/year among children aged $<15$ years [16]. Figures as high as 5 cases/100,000/year have been reported from some districts in Bangladesh [7].
Unlike other autoimmune diseases, males are typically affected more than females $[10,16,20,21]$. However, male predilection is found in other immune-mediated peripheral neuropathies like chronic inflammatory demyelinating polyneuropathy, multifocal motor neuropathy and Miller-Fisher syndrome [4]. Our study showed a malefemale ratio of 1.3:1. Individual studies report ratios of 1.5 to 2.7 males to 1 female [20]. However, estimated 662 children reported in different studies have shown a male-female ratio of 1.3:1. Likewise, a total of 1607 patients of all ages reported in different studies have shown a similar ratio of 1.3:1 [20]. Pooled data about the cases of GBS in Latin America showed the exact same ratio [21]. This indicates that the higher preponderance of males in individual studies is likely to be the product of the confounding effect of sample size (Simpson's paradox) [20].

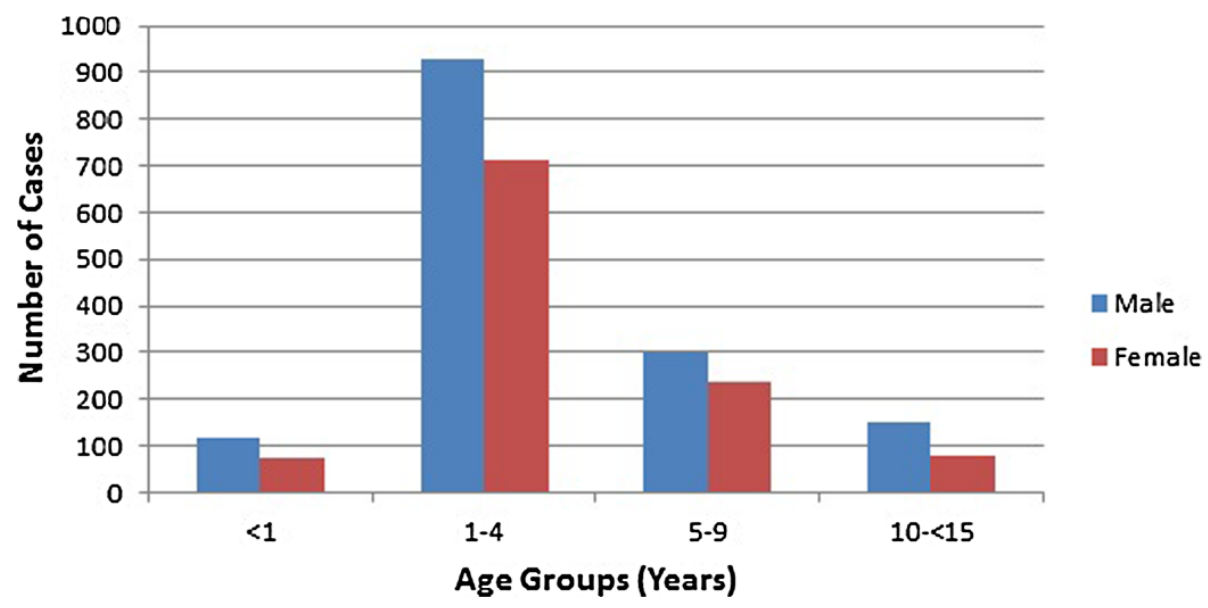

Figure 2 Number of cases with Guillain-Barré syndrome per age group, Iraq, 1997-2011. 


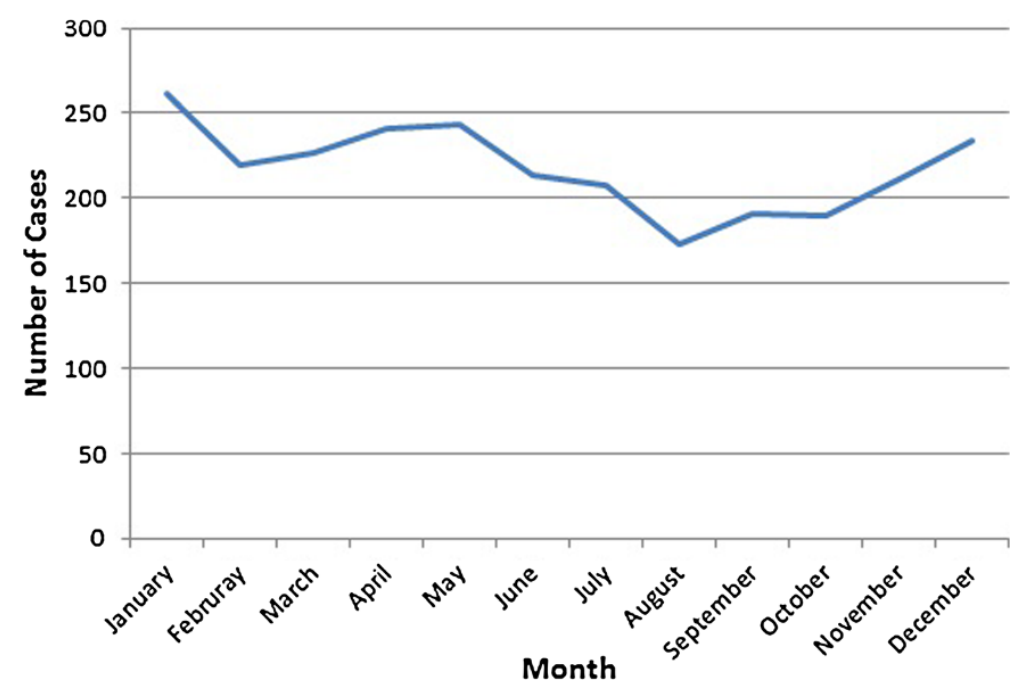

Figure 3 Number of cases with Guillain-Barré syndrome per month, Iraq, 1997-2011.

In accordance with other reports, children $1-4$ years old were the most commonly affected age group with GBS in our study $[9,10,22,23]$. This is believed to be due to their relatively high susceptibility to infections in this age group and the increased susceptibility to the young myelinated peripheral nerves to demyelination [22,23]. Southern provinces have a statistically significant higher incidence of GBS compared to both Central and Northern ones. Although no specific reason was found, geographic variation in the incidence of disease in Iraq may be due to differences in the infection rates and climate among the different regions $[7,9]$.

Table 2 Selected clinical characteristics of cases with Guillain-Barré syndrome, Iraq, 1997-2011

\begin{tabular}{ll}
\hline Features & Cases (\%) \\
\hline Fever at the onset of paralysis & $2449(93.8)$ \\
Yes & $1358(55.4)$ \\
No & $1091(44.5)$ \\
Progression to the maximum paralysis & $2523(96.6)$ \\
within $\mathbf{4}$ days of onset & \\
Yes & $2450(97.1)$ \\
No & $73(2.9)$ \\
Residual paralysis at least $\mathbf{6 0}$ days from & $2343(89.7)$ \\
onset & \\
Yes & $619(26.4)$ \\
No & $1724(73.6)$ \\
Survival at least $\mathbf{6 0}$ days from onset & $2461(94.2)$ \\
Alive & $2343(95.2)$ \\
Dead & $118(4.8)$ \\
\hline
\end{tabular}

Many studies have addressed the seasonality in the incidence of GBS, $[9,15,16,24,25]$ only a few demonstrated a significant seasonal trend [18,24,26,27]. The lack of clear seasonal association may be due to the fact that the respiratory and enteric infections that precede GBS have opposite seasonal patterns [17]. The higher number of cases reported in winter and spring in our study is similar to reports from Southern Iran and Kuwait [18,28]. In general, different countries have different clustering patterns of cases, which might reflect the heterogeneity of the infectious agents that trigger the disease. The same reason may explain the higher number of cases reported outside the capital city of provinces, dominated by rural areas.

Although not classically attributed to the disease process of GBS $[9,29]$, fever at the onset of paralysis is reported from previous studies and may be attributed to the effect of the triggering infectious disease $[9,21,30]$. Our study revealed that $55.4 \%$ of cases had fever at the onset of paralysis. As it might be expected from a study that is primarily concerned about AFP surveillance as a sensitive measure to detect cases of poliomyelitis, specific details about the progression pattern of weakness, sensory involvement, and dysautonomia in patients with GBS were not recorded in the study.

Although information about respiratory muscle involvement were only recorded for 1166 (44.7\%) of patients, cumulative survival was significantly lower in those with respiratory muscle involvement. Likewise, the cumulative survival was significantly lower among those living outside the capital city of province. However, the latter association was insignificant when stratified by respiratory muscle involvement. This indicates that household location is not an independent cause of death per 


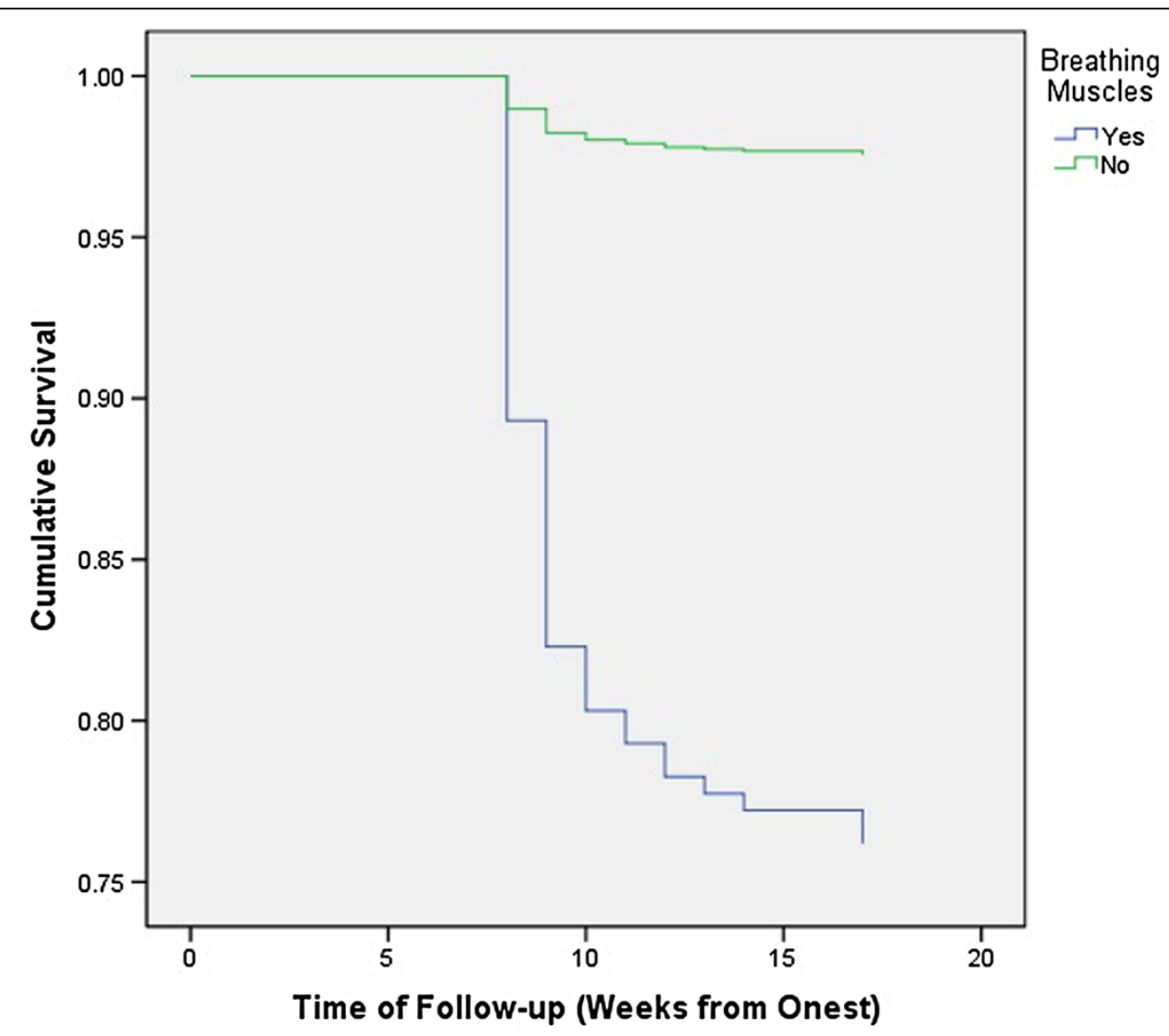

Figure 4 Cumulative survival of cases with Guillain-Barré syndrome based on history of respiratory muscle paralysis, Iraq, $1997-2011$.

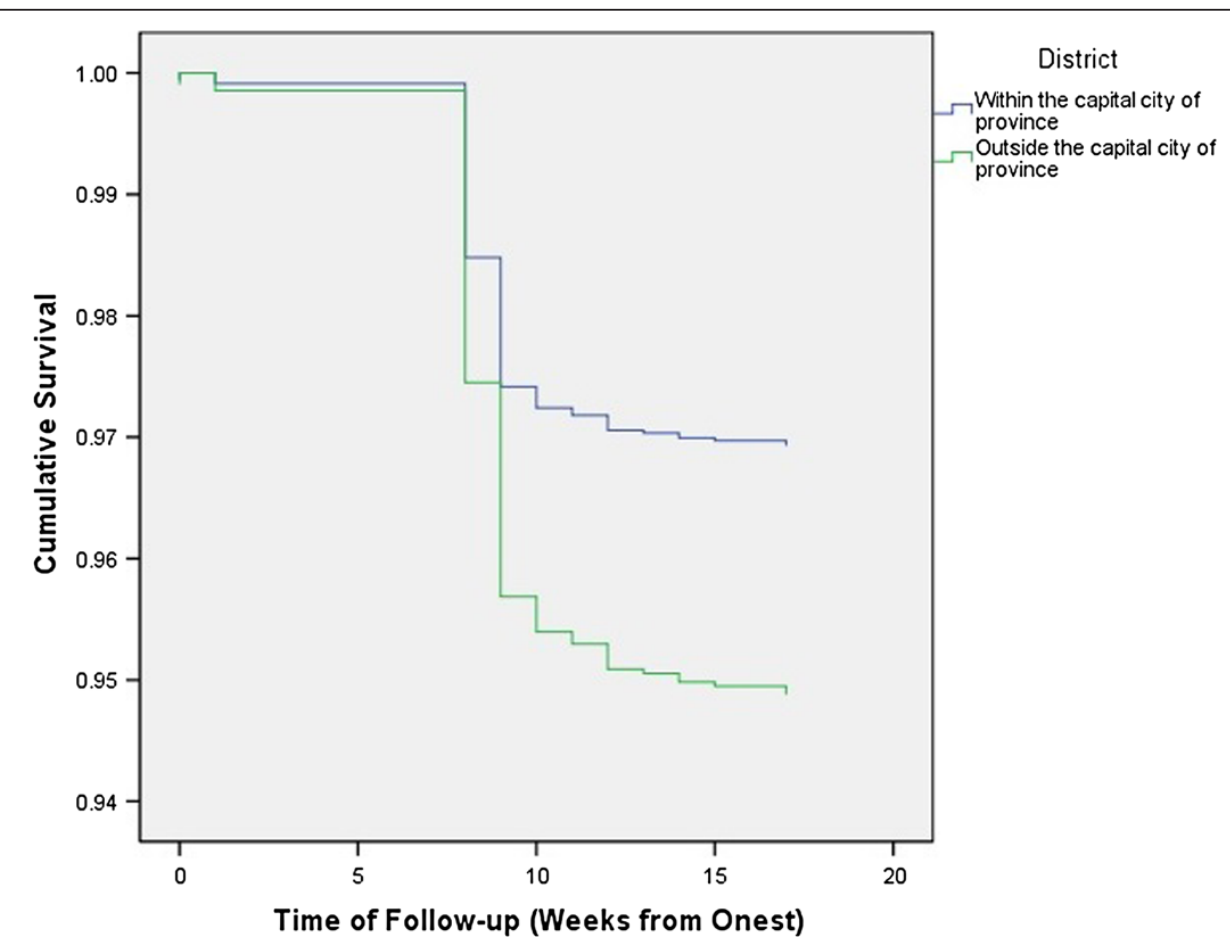

Figure 5 Cumulative survival of cases with Guillain-Barré syndrome based on their household location within the province, Iraq, 1997-2011. 


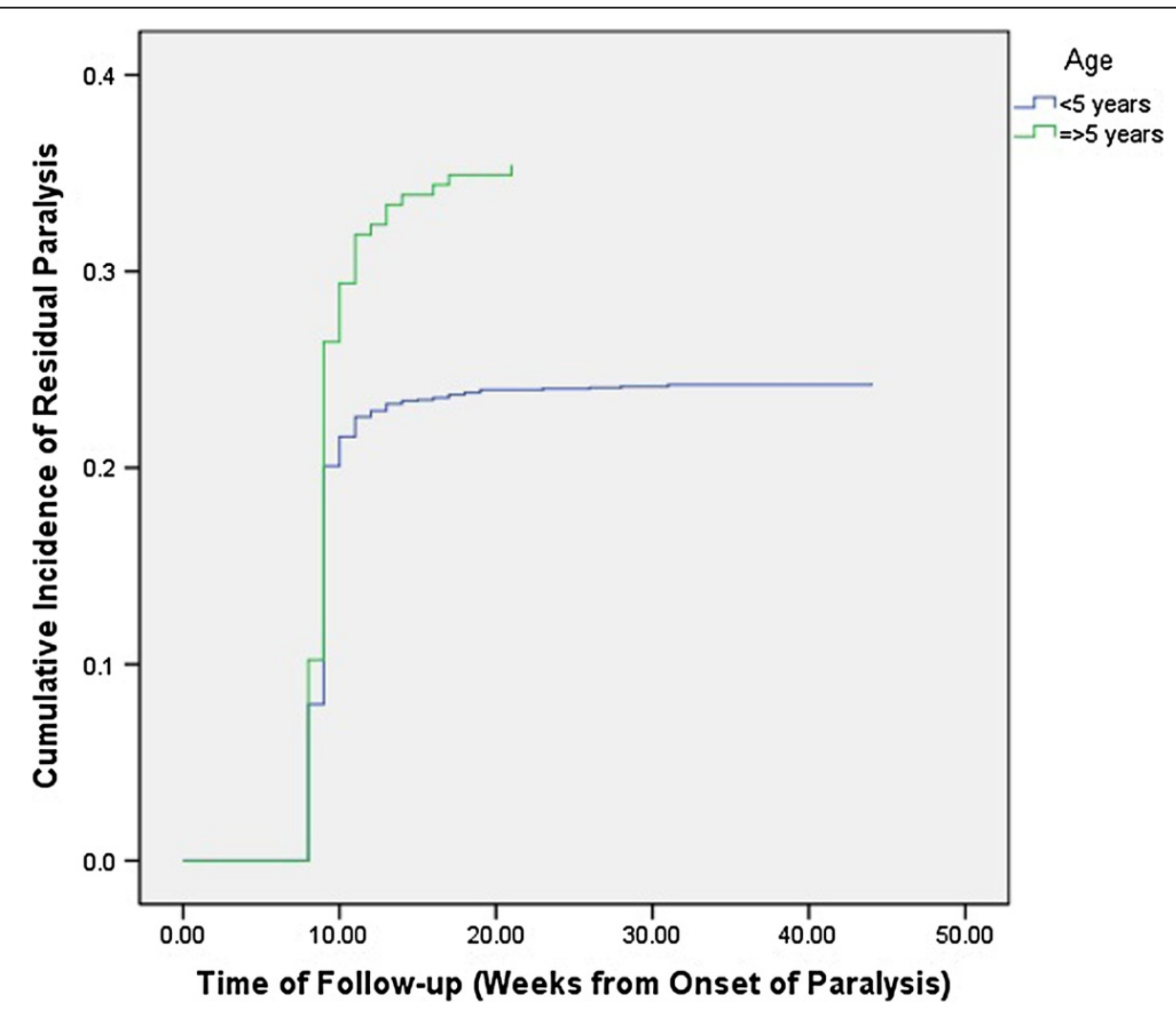

Figure 6 Cumulative incidence of residual paralysis among cases with Guillain-Barré syndrome, Iraq, 1997-2011.

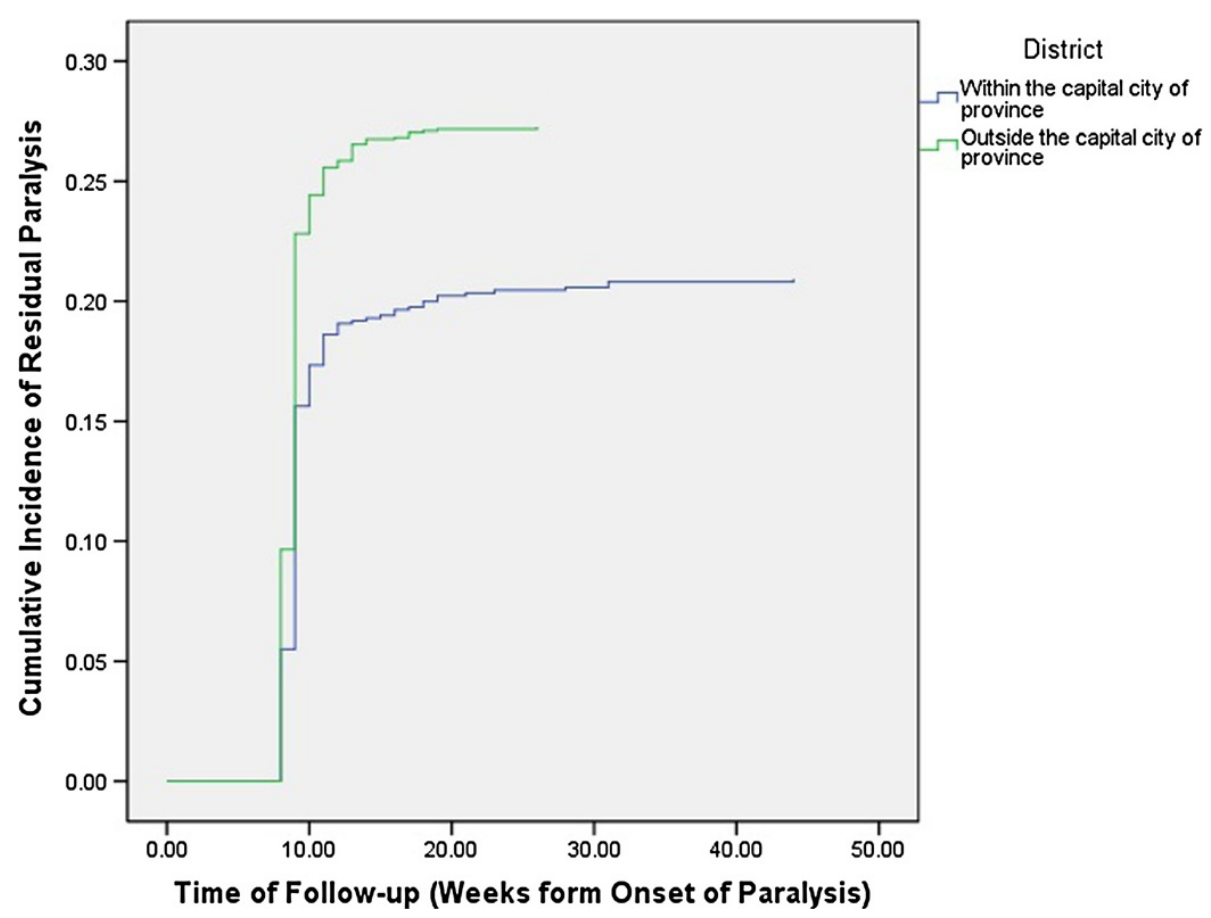

Figure 7 Cumulative incidence of residual weakness among cases with Guillain-Barré syndrome based on their household location within the province, Iraq, 1997-2011. 
se, but rather causes death via respiratory paralysis, which plays a "mediating" effect. Furthermore, the association between household location and respiratory paralysis was insignificant too $(p=.12)$, indicating that although respiratory paralysis occurs equally among those living inside and outside the capital city of province; the latter group are more likely die from it. This finding may be due to one or more of: differences of the inciting factors, delayed diagnosis in the rural areas, and inaccessibility to the required intensive care in those areas. Respiratory intensive care units do not exist in the vast majority of hospitals serving the rural communities in Iraq.

The risk of residual paralysis was higher among children above the age of 5 years. In general, the prognosis of GBS is shown to be better among younger age groups, although comparisons were generally made with adults [31-33]. In the largest prospective study by Korinthenberg et al., $96 \%$ of children were either asymptomatic or had minor symptoms at the end of the 288-day observation period [34]. This might reflect poorer axonal outgrowth and regeneration and less effective remyelinization process with increasing age [32]. Again, lower quality of and access to health care might underlie the increased risk of residual paralysis among cases residing outside the capital city of province.

The current study is the first to be done in Iraq involving analysis of nation-wide data over 15 years of study. It presents information about the overall incidence of disease, as well as the differences in disease incidence with time, age, gender, season, province of residence, and household location within the province of residence. It also provides information about the case-fatality rate of the disease and the likelihood of developing residual weakness following the resolution of acute disease, with emphasis on gender, age, and household location differences in those adverse outcomes. The sensitivity of AFP investigation was 2.5 cases/100,000 population below the age of 15 (above the WHO-recommended cut-off level of $1 / 100,000)$ and completeness of reporting was $96 \%$ (above the above the WHO-recommended cut-off level of $80 \%$ ). These two performance indicators imply that the vast majority of GBS cases among children below 15 years were effectively detected and recorded in the current database. However, since the data were collected for the purpose of acute flaccid surveillance as a strategy for detecting cases of poliomyelitis, the study provides limited information about the clinical features and subtypes of disease. Future studies are needed to at least identify the main 4 main subtypes of GBS, including: acute inflammatory demyelinating polyradiculoneuropathy (AIDP), acute motor axonal neuropathy (AMAN) and acute motor and sensory axonal neuropathy (AMSAN), and Miller Fisher syndrome [16]. Likewise, no data were available about the treatment modalities used for treating GBS cases. However, IVIG therapy remains largely unavailable in Iraq. Information about the history of preceding respiratory and gastrointestinal infection needs to be documented in future studies.

\section{Conclusions}

The incidence, age and gender distribution, and seasonality of GBS among Iraqi children is similar to those reported from other previous studies. It is the most important cause of AFP, especially in those between the age of 1 to 4 years living in rural areas.

\section{Competing interests}

The authors declare that they have no competing interests.

\section{Authors' contributions}

JJ has made substantial contributions to design of the study, data analysis, and writing and submitting the manuscript. KM, AN, YK, SA, and FH have contributed in data acquisition and manuscript revision. MI and AK have supervised study design and data analysis, as well as critically revised the manuscript. All authors have read and approved the final manuscript.

\section{Author details}

${ }^{1}$ School of Medicine/ Faculty of Medical Sciences/ University of Duhok, Nakhoshkhana Street, Duhok, Kurdistan Region, Iraq. ${ }^{2}$ Internal Medicine, Ohio State University, Columbus, Ohio, USA. ${ }^{3}$ Directorate of Preventive Health Affairs, Directorate General of Health, Mazi Street, Duhok, Kurdistan Region, Iraq. ${ }^{4}$ National Communicable Disease Control, Ministry of Health, Bab Al Mudam Area, Baghdad, Iraq. ${ }^{5}$ AFP Surveillance Laboratory, Ministry of Health, Bab Al Mudam Area, Baghdad, Iraq. ${ }^{6}$ College of Public Health, University of Nebraska Medical Center, Omaha, Nebraska, USA. ${ }^{7}$ Division of Infectious Diseases/Department of Internal Medicine, University of Nebraska Medical Center, Omaha, Nebraska, USA.

Received: 19 July 2013 Accepted: 5 December 2013 Published: 10 December 2013

\section{References}

1. Beherman R, Kliegman R, Jenson H: Nelson's Textbook of Pediatrics. Philadelphia: Saunders; 2003.

2. Kasper D, Braunwals E, Hauser S, Longo D, Jameson L, Antony F: Harrison's principles of internal medicine. New York: McGraw-Hill Professional; 2005.

3. Hughes RA, Cornblath DR: Guillain-Barre syndrome. Lancet 2005 366(9497):1653-1666

4. Kuwabara S: Guillain-Barre syndrome: epidemiology, pathophysiology and management. Drugs 2004, 64(6):597-610.

5. Oomes PG, Jacobs BC, Hazenberg MP, Banffer JR, van der Meche FG: Anti-GM1 lgG antibodies and Campylobacter bacteria in Guillain-Barre syndrome: evidence of molecular mimicry. Ann Neurol 1995, 38(2):170-175.

6. Sladky JT: Guillain-Barre syndrome in children. J Child Neurol 2004, 19(3):191-200.

7. Islam Z, Jacobs BC, van Belkum A, Mohammad $Q D$, Islam MB, Herbrink $P$ Diorditsa S, Luby SP, Talukder KA, Endtz HP: Axonal variant of Guillain-Barre syndrome associated with Campylobacter infection in Bangladesh. Neurology 2010, 74(7):581-587.

8. Lam RM, Tsang TH, Chan KY, Lau YL, Lim WL, Lam TH, Leung NK, National Committee for the Certification of Wild Poliovirus Eradication: Surveillance of acute flaccid paralysis in Hong Kong: 1997 to 2002. Hong Kong Med J 2005, 11(3):164-173.

9. Landaverde JM, Danovaro-Holliday MC, Trumbo SP, Pacis-Tirso CL, Ruiz-Matus C: Guillain-Barre syndrome in children aged $<15$ years in Latin America and the Caribbean: baseline rates in the context of the influenza A (H1N1) pandemic. J Infect Dis 2010, 201(5):746-750.

10. Molinero MR, Varon D, Holden KR, Sladky JT, Molina IB, Cleaves F: Epidemiology of childhood Guillain-Barre syndrome as a cause of acute flaccid paralysis in Honduras: 1989-1999. J Child Neurol 2003, 18(11):741-747. 
11. Morris AM, Elliott EJ, D'Souza RM, Antony J, Kennett M, Longbottom H: Acute flaccid paralysis in Australian children. J Paediatr Child Health 2003, 39(1):22-26

12. Oostvogel PM, Spaendonck MA, Hirasing RA, van Loon AM: Surveillance of acute flaccid paralysis in The Netherlands, 1992-94. Bull World Health Organ 1998, 76(1):55-62

13. Poorolajal J, Ghasemi S, Farahani LN, Hosseini AS, Bathaei SJ, Zahiri A: Evaluation of acute flaccid paralysis in hamadan, iran from 2002 to 2009. Epidemiol Health 2011, 33:e2011011.

14. Saraswathy TS, Zahrin HN, Apandi MY, Kurup D, Rohani J, Zainah S, Khairullah NS: Acute flaccid paralysis surveillance: looking beyond the global poliomyelitis eradication initiative. Southeast Asian J Trop Med Public Health 2008, 39(6):1033-1039.

15. Chroni E, Papapetropoulos S, Gioldasis G, Ellul J, Diamadopoulos N, Papapetropoulos T: Guillain-Barre syndrome in Greece: seasonality and other clinico-epidemiological features. Eur J Neurol 2004 11(6):383-388.

16. McGrogan A, Madle GC, Seaman HE, de Vries CS: The epidemiology of Guillain-Barre syndrome worldwide. A systematic literature review. Neuroepidemiology 2009, 32(2):150-163.

17. Hughes RA, Rees JH: Clinical and epidemiologic features of Guillain-Barre syndrome. J Infect Dis 1997, 176(Suppl 2):S92-S98.

18. Borhani Haghighi A, Banihashemi MA, Zamiri N, Sabayan B, Heydari ST, Safari A, Lankarani KB: Seasonal variation of Guillain-Barre syndrome admission in a large tertiary referral center in southern Iran: a 10 year analysis. Acta Neurol Taiwan 2012, 21(2):60-63.

19. World Health Organization, Iraqi Ministry of Health: Acute Flaccid Paralysis Field Manual. Baghdad: WHO \& Iraqi MOH; 2009.

20. Ammache $Z$, Afifi AK, Brown CK, Kimura J: Childhood Guillain-Barre syndrome: clinical and electrophysiologic features predictive of outcome. J Child Neurol 2001, 16(7):477-483.

21. Olive JM, Castillo C, Castro RG, de Quadros CA: Epidemiologic study of Guillain-Barre syndrome in children $<15$ years of age in Latin America. J Infect Dis 1997, 175(Suppl 1):S160-S164.

22. Koul R, Al-Futaisi A, Chacko A, Fazalullah M, Nabhani SA, Al-Awaidy S, Al-Busaidy S, Al-Mahrooqi S: Clinical characteristics of childhood guillain-barre syndrome. Oman Med J 2008, 23(3):158-161.

23. Rantala H, Cherry JD, Shields WD, Uhari M: Epidemiology of Guillain-Barre syndrome in children: relationship of oral polio vaccine administration to occurrence. J Pediatr 1994, 124(2):220-223.

24. Nachamkin I, Arzarte Barbosa P, Ung H, Lobato C, Gonzalez Rivera A, Rodriguez P, Garcia Briseno A, Cordero LM, Garcia Perea L, Perez JC, Ribera M, Aldama PC, Guiterrez GD, Sarnat LF, Garcia MR, Veitch J, Fitzgerald C, Cornblath DR, Rodriguez Pinto M, Griffin JW, Willison HJ, Asbury AK, McKhann GM: Patterns of Guillain-Barre syndrome in children: results from a Mexican population. Neurology 2007, 69(17):1665-1671.

25. Van Koningsveld R, Van Doorn PA, Schmitz PI, Ang CW, Van der Meche FG: Mild forms of Guillain-Barre syndrome in an epidemiologic survey in The Netherlands. Neurology 2000, 54(3):620-625

26. Jiang GX, Cheng Q, Link H, de Pedro-Cuesta J: Epidemiological features of Guillain-Barre syndrome in Sweden, 1978-93. J Neurol Neurosurg Psychiatry 1997, 62(5):447-453.

27. Lyu RK, Tang LM, Cheng SY, Hsu WC, Chen ST: Guillain-Barre syndrome in Taiwan: a clinical study of 167 patients. J Neurol Neurosurg Psychiatry 1997, 63(4):494-500.

28. Ismail EA, Shabani IS, Badawi M, Sanaa H, Madi S, Al-Tawari A, Nadi H, Zaki M, Al-saleh Q: An epidemiologic, clinical, and therapeutic study of childhood Guillain-Barre syndrome in Kuwait: is it related to the oral polio vaccine? J Child Neurol 1998, 13(10):488-492.

29. van Doorn PA, Ruts $L$, Jacobs $B C$ : Clinical features, pathogenesis, and treatment of Guillain-Barre syndrome. Lancet Neurol 2008, 7(10):939-950.

30. Koga M, Yuki N, Hirata K: Antecedent symptoms in Guillain-Barre syndrome: an important indicator for clinical and serological subgroups. Acta Neurol Scand 2001, 103(5):278-287.

31. Kalra V, Sankhyan N, Sharma S, Gulati S, Choudhry R, Dhawan B: Outcome in childhood Guillain-Barre syndrome. Indian J Pediatr 2009, 76(8):795-799.

32. Anonymous: The prognosis and main prognostic indicators of guillain-barre syndrome. A multicentre prospective study of 297 patients. The Italian guillain-barre study group. Brain 1996, 119(Pt 6):2053-2061. Pt 6.
33. Walgaard $C$, Lingsma HF, Ruts L, van Doorn PA, Steyerberg EW, Jacobs BC: Early recognition of poor prognosis in Guillain-Barre syndrome. Neurology 2011, 76(11):968-975

34. Korinthenberg R, Schessl J, Kirschner J: Clinical presentation and course of childhood Guillain-Barre syndrome: a prospective multicentre study. Neuropediatrics 2007, 38(1):10.

doi:10.1186/1471-2377-13-195

Cite this article as: Jasem et al: Guillain-Barré syndrome as a cause of acute flaccid paralysis in Iraqi children: a result of 15 years of nation-wide study. BMC Neurology 2013 13:195.

\section{Submit your next manuscript to BioMed Central and take full advantage of:}

- Convenient online submission

- Thorough peer review

- No space constraints or color figure charges

- Immediate publication on acceptance

- Inclusion in PubMed, CAS, Scopus and Google Scholar

- Research which is freely available for redistribution 